\title{
Microwave Synthesis of Supported Au and Pd Nanoparticle Catalysts for CO Oxidation
}

Garry Glaspell, Lindsay Fuoco and M. Samy El-Shall ${ }^{*}$

Department of Chemistry, Virginia Commonwealth University

Richmond, Virginia 21284-2006 


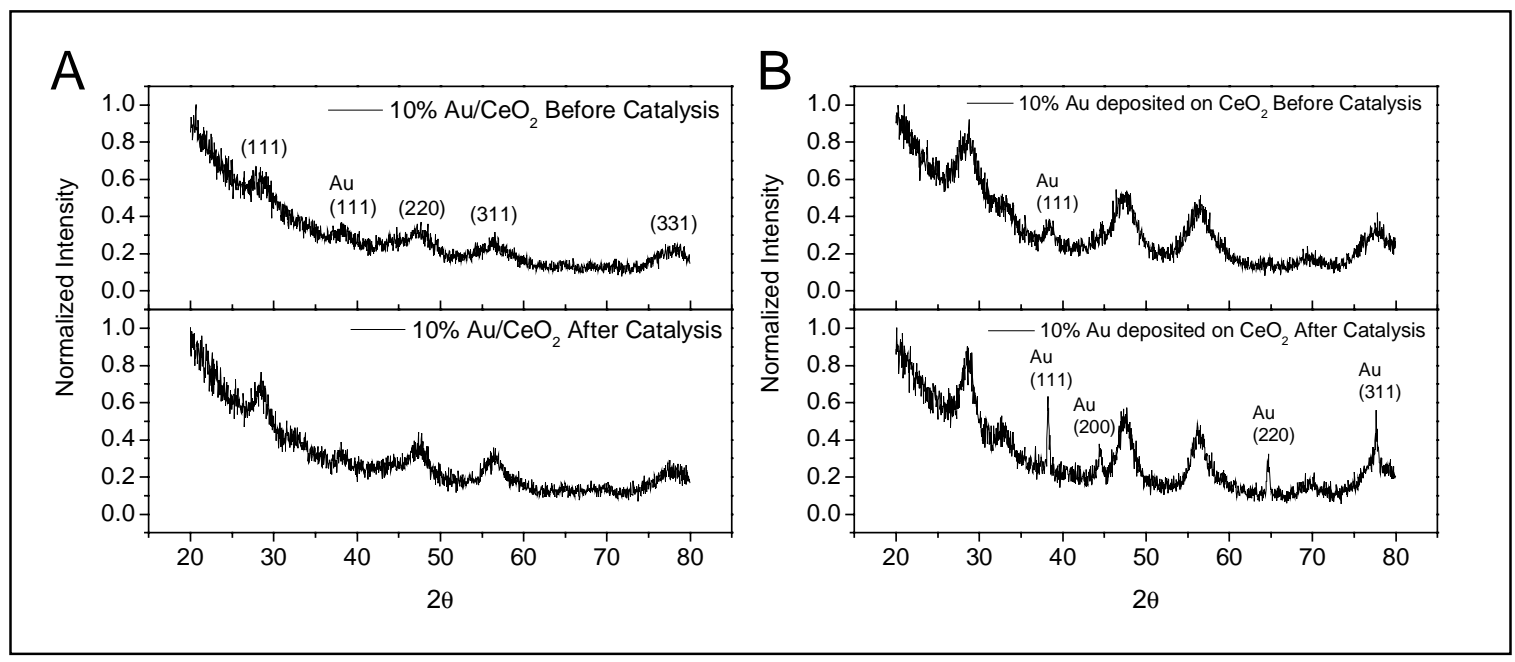

Figure S-A. $\mathrm{XRD}$ of $10 \% \mathrm{Au} / \mathrm{CeO}_{2}$ produced via microwave irradiation as-prepared (top) and after catalysis (bottom). The patterns match with $\mathrm{CeO}_{2}$ (PDF: 00-034-0394) and Au (PDF: 03-065-8601) in the database..

Figure S-B. $\mathrm{XRD}$ of $10 \% \mathrm{Au} / \mathrm{CeO}_{2}$ precipatated separately produced via microwave irradiation as-prepared (top) and after catalysis (bottom). The patterns match with $\mathrm{CeO}_{2}$ (PDF: 00-034-0394) and Au (PDF: 03-065-8601) in the database. 